pineapple juice, using I gram of dry juice, neutralized with sodium hydroxide, to $\mathrm{r}$ o grams of the albumen in $35 \mathrm{cc}$. $\mathrm{O}$. I per cent. sodium hydroxide solution, with 3 hours' digestion, left a residue of 2 cc., reading after 18 hours, while a blank read 4 I cc.

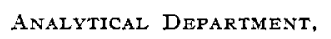

\section{THE BROMINE AND IODOMETRIC METHODS FOR THE VOLUMETRIC DETERMINATION OF CRESOL. ${ }^{2}$}

By C. M. PeNCe.

Received January 17, 1912.

Of the several methods suggested for the volumetric determination of phenol, the bromine method has received the most consideration, and in almost every instance where bromine has been used an attempt has been made to substitute iodine in its stead.

The popularity of the bromine method is no doubt due to two causes: First, to the fact that it answers the demand for a reliable method in the determination of the first member of the series, namely, pheno1; second, to the ease in manipulation resulting from the use of the Koppeschaar bromine solution.

Now cresol is the next member of the homologous series; however, it presents, upon treatment with bromine solution and acid, problems quite different from that of phenol. Since commercial cresol is a mixture of the three isomeric phenols $o-, m$ - and $p$-cresol, the presence of the $\mathrm{CH}_{3}$ group in the different positions necessitates the formation of compounds structurally unlike and empirically the same, and also causes, in the case of meta cresol, the formation of compounds both structurally and empirically different from those formed by 0 - and p-cresols. In 2,4,6-tribrom phenol brom, the bromine occupies both the $o$ - and $p$-positions. Now in the case of $O$ - and $p$-cresol the $\mathrm{CH}_{3}$ group occupies the $o$ - and $p$-positions and only dibromcresol and dibromcresol brom compounds can be readily formed since the $\mathrm{CH}_{3}$ group is more difficult to replace by free $\mathrm{Br}$ than is a hydrogen atom. However, the $\mathrm{CH}_{3}$ group is slowly replaced and prolonged standing (several days) results in formation of tribromphenol brom-W. Autenrieth and F. Beuttela have recently published the results of an extensive investigation along this line.

Meta cresol forms tribrom- $m$-cresol brom since the $\mathrm{CH}_{3}$ group is not in the position that the $\mathrm{Br}$ atom would occupy.

H. Ditz and F. Cedivoda 3 have proposed a bromine method for cresols depending upon the difference in speed of reactions between bromine and $m$-cresol on the one hand and bromine and $o-$ and $p$-cresols on the other. If either $o$ - or $p$-cresol is mixed with a known excess of bromine solution, acidified with ( $r: r)$ hydrochloric acid and agitated for $r$ min., on adding $K I$ and titrating with thiosulfate it will be found that each molecule of $o$ - and $p$-cresols has

1 Read at A. C. S, meeting at Washington, D. C., December, 1911.

2 'Ueber die Bestimmung des Phenols, Salicyl alkohols, der Salicylsäure und $p$-oxybenzoësäure als Tribrom phenol brom" (Autenrieth und Beutel), Archiv der Pharm., 1910, 112.

3 "Reactions of Bromine with Phenol and the Cresols, a Process for Calculating the Composition of Mixtures Thereof"' (Ditz and Cedivoda). $Z$. angew Chem., 1899, 873 and 897 . Abstr.-Analyst, 25, 74. absorbed 2 atoms of bromine. Under the same conditions each molecule of $m$-cresol will absorb 3 atoms of bromine. Now if acidification is effected by concentrated sulfuric acid, the solution shaken for five minutes and insoluble matter removed by filtration, 3 atoms of bromine will have combined with each molecule of $o$ - and $p$-cresol, 4 atoms with each molecule of $m$-cresol.

The above method depends for its success upon definitely fixed conditions; namely: time, strength of acid, excess of bromine, etc. F. Russig and G. Fortmann ${ }^{x}$ have criticized this method and H. Ditz ${ }^{2}$ has replied at length.

The present study of the reaction of bromine and iodine upon the different cresols was made for the purpose of finding which of the cresols were amenable to assay by processes which do not require previous knowledge concerning the percentage of product, that is, by processes dependent upon the formation of definitely fixed, comparatively stable, final products; namely: compounds containing three atoms of bromine in combination.

Samples of the individual cresols were redistilled and volumetric solutions prepared from the distillates, small amounts of $\mathrm{N} / 2 \mathrm{NaOH}$ being added to facilitate solution. Aliquot portions of these solutions were used in the several determinations.

The results appearing in the tables are based upon the formation of dibromcresol brom and tribrom compounds on the one hand and diiodo compounds on the other.

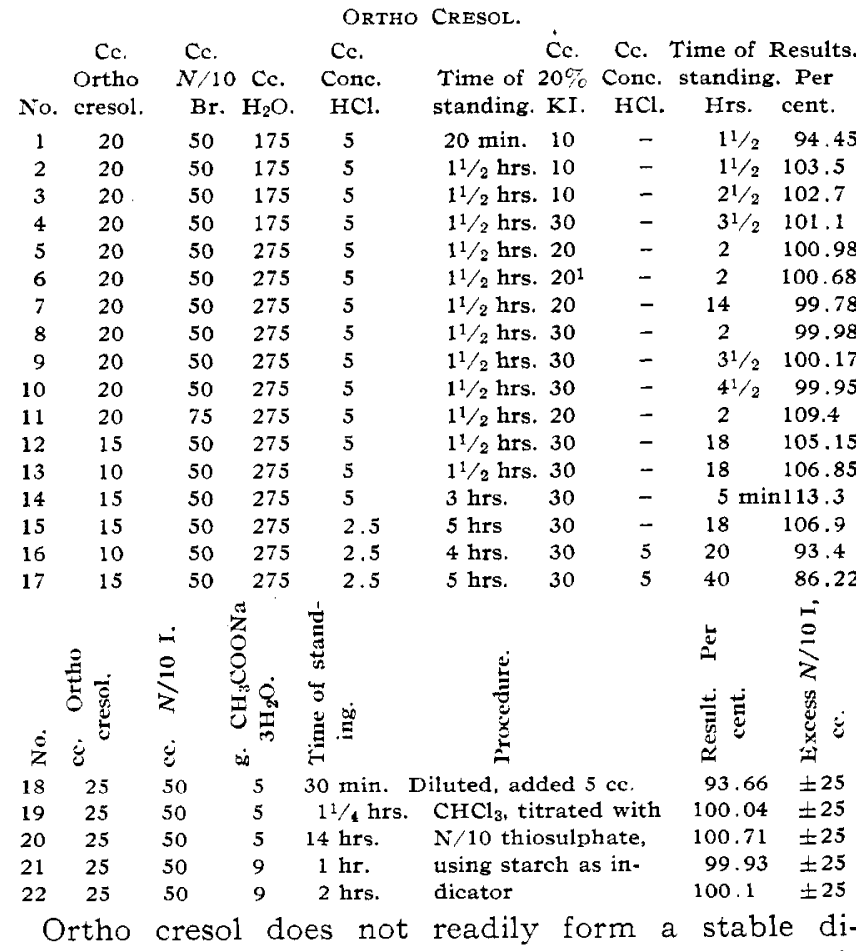
brom-o-cresol brom or a tribrom compound as is evidenced in Exp. I. However, upon $\mathrm{I}^{\mathrm{r}} / \mathbf{2}$ hours' stand-

1 "Estimation of Cresol" (Russig and Fortmann), $Z$, angew. Chem., 1901, 157-60. Abstr.- I. Chem. Soc., 1901, II, 289.

2 "Estimation of Cresol" (H. Ditz), Z, angew. Chem., 1901, 160-5. Abstr.-J. Chem. Soc., 1901, II, 289.

${ }^{3}$ Heated to $40^{\circ} \mathrm{C}$. after addition of $\mathrm{KI}$. 
ing more than sufficient $\mathrm{Br}$ is absorbed for the formation of these compounds and the addition of io to $30 \mathrm{cc}$. of $\mathrm{I} 0$ per cent. KI with from $\mathrm{I}^{\mathrm{r} / 2}$ to $3^{\mathrm{I} / 2}$ hours' standing does not result in the liberation of the bromine necessary for the formation of either dibrom-o-cresol or a tribrom compound as would occur if reaction proceeded in a manner strictly analogous to phenol (Exps. 2, 3, and 4).

Now a greater dilution results in the absorption of a smaller quantity of bromine but results are still too high, Exps. 5 and 6 . Increased standing after addition of $20 \mathrm{cc}$. 20 per cent. KI causes a reversal with practically theoretical quantities of bromine absorbed, the time of standing being materially reduced upon increase in the quantity of $\mathrm{KI}$ (Exps. $7,8,9$ and Io).

An increase in concentration of bromine in contact with o-cresol as is effected by larger quantities of $\mathrm{Br}$ solution or a decrease in the quantity of cresol solution results in the absorption of much more than the theoreticalquantity of bromine and even upon prolonged standing in contact with increased quantities of $\mathrm{KI}$, suitable reversal does not take place (Exps. I I, I 2 , I3, I 4 and 15 ).

The effect due to increase in the quantity of acid is very marked. When bromine is liberated by onehalf the usual quantity of concentrated $\mathrm{HCl}$ sufficient reversal does not take place after addition of $\mathrm{KI}$ (Exps. $\mathrm{r}_{4}$ and $\mathrm{I}_{5}$ ). However, when an additional 5 cc. of concentrated $\mathrm{HCl}$ are added at the same time as the $\mathrm{KI}$, the reversal causes far less than theoretical quantities of bromine to remain in combination (Exps. I 6 and 17 ).

Thus it will be seen that practical results dependent upon the formation of a dibromcresol brom or tribrom compound can not be obtained except by definitely fixing the several conditions of the experiment in pursuance of which a previous knowledge of the percentage of 0 -cresol is required.

Now when iodine acts upon o-cresol, diiodo-ocresol is formed. The reaction is reversible and sodium acetate is added to unite with the hydriodic acid produced by the substituting iodine, thereby causing the reaction to proceed to completeness (Exps. I 8, I 9, 20, 2 I and 22). In this case, the reaction ends with the formation of the diiodo compound, hence it is made the basis of the following method for the determination of $o$-cresol.

Dissolve $2-2.5 \mathrm{~g}$. $O$-cresol in distilled water containing about io cc. $\mathrm{N} / 2 \mathrm{NaOH}$ to facilitate solution. Dilute to $1000 \mathrm{cc}$. Withdraw $25 \mathrm{cc}$. portions and place in a $500 \mathrm{cc}$. glass stoppered receptacle. Add to the receptacle approximately 9 grams sodium acetate and then $50 \mathrm{cc}$. $N /$ io I solution. Let stand I hour, dilute with $100-200 \mathrm{cc}$. distilled water, add a few cc. of $\mathrm{CHCl}_{3}$ to dissolve the precipitated diiodocresol and titrate with $N /$ Io thiosulphate, using starch as an indicator.

I cc. $N /$ Io I $=0.00268$ I g. o-cresol.

Meta cresol does not rapidly form tribrom-mcresol brom with the subsequent formation of tribrom-m-cresol upon standing in contact with $\mathrm{KI}$

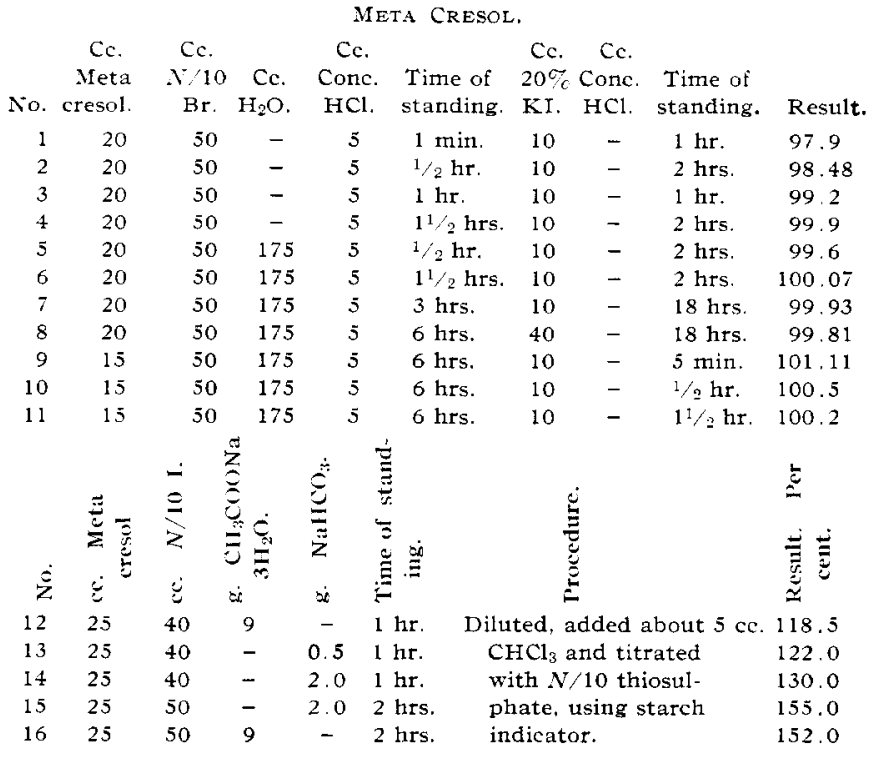

(Exps. I, 2 and 3 ). If the $m$-cresol solution stands $\mathrm{r} / 2$ hours in contact with the bromine and then Io cc. 20 per cent. KI a re added and solution is allowed to stand $I$ to 2 hours, all the cresol is converted into tribrom-m-cresol (Exp. 4).

Dilution permits a more rapid reaction which almost completes itself in $\mathrm{r} / 2$ hour. The addition of $\mathrm{KI}$ causes a complete reversal even though the time of standing in contact with free bromine has been much prolonged (Exps. 5, 6, 7, 8, 9, 10 and I I).

It is thus apparent that $m$-cresol may be determined by a conversion into the tribrom compound.

Upon the other hand, when iodine ${ }^{r}$ acts upon $m$-cresol in the presence of sodium acetate or sodium bicarbonate, a diiodo compound that may be made the basis of calculation is not produced. More than the theoretical quantity of iodine is absorbed (Exps. I 2, I $3, I_{4}, I_{5}$ and I6).

\begin{tabular}{|c|c|c|c|c|c|c|c|c|c|}
\hline No. & $\begin{array}{c}\text { Cc. } \\
\text { Para } \\
\text { cresol. }\end{array}$ & $\begin{array}{c}\text { Cc. } \\
N / 10 \\
\text { Br. }\end{array}$ & $\begin{array}{c}\mathrm{Cc} \\
\mathrm{H}, 2\end{array}$ & $\begin{array}{l}\text { Ce. } \\
\text { Cone. } \\
\text { HCl. }\end{array}$ & $\begin{array}{l}\text { Time of } \\
\text { standing. }\end{array}$ & $\begin{array}{c}\mathrm{Cc} \\
20^{c}, \\
\mathrm{KI}\end{array}$ & $\begin{array}{l}\text { Cc. } \\
\text { Cone } \\
\text { HCl.. }\end{array}$ & $\begin{array}{l}\text { Time of } \\
\text { standing. }\end{array}$ & $\begin{array}{l}\text { Result. } \\
\text { Per } \\
\text { cent. }\end{array}$ \\
\hline 1 & 20 & 50 & 275 & 5 & $1 \mathrm{hr}$. & 10 & - & 2 hrs. & 81.1 \\
\hline 2 & 20 & 50 & 275 & 5 & $4^{1 / 2}$ hrs. & 10 & - & $18 \mathrm{hrs}$ & 95.73 \\
\hline 3 & 20 & 50 & - & 5 & $41 / 2 \mathrm{hr}$ & 10 & - & 18 hrs. & 76.35 \\
\hline 4 & 15 & 50 & 275 & 2.5 & 3 hrs. & 10 & - & $5 \mathrm{~min}$ & 97.34 \\
\hline 5 & 15 & 50 & 275 & 5 & $1^{1 / 2}$ hrs. & 30 & - & 18 hrs. & 89.73 \\
\hline 6 & 10 & 25 & 200 & 2.5 & 3 hrs. & 10 & - & 18 hrs. & 101.8 \\
\hline 7 & 10 & 25 & 200 & 2.5 & 3 hrs. & 20 & - & $18 \mathrm{hrs.}$ & 101.75 \\
\hline 8 & 10 & 25 & 200 & 5 hrs. & 3 hrs. & 10 & - & $18 \mathrm{hrs.}$ & 97.7 \\
\hline 9 & 10 & 25 & 200 & 2.5 & $8^{1 / 2}$ hrs. & 10 & - & $16 \mathrm{hrs.}$ & 104.6 \\
\hline 10 & 10 & 25 & 200 & 2.5 & 4 hrs. & 30 & 5 & $20 \mathrm{hrs}$. & 84.94 \\
\hline 11 & 10 & 25 & 200 & 2.5 & $5 \mathrm{hrs}$ & 30 & 5 & $40 \mathrm{hrs}$. & 82,90 \\
\hline$\dot{z}$ & 泀 & $\therefore$ & $\underbrace{2}$ & 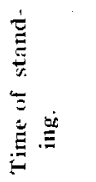 & & 总 & & 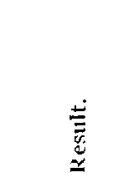 & 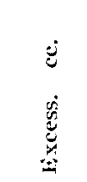 \\
\hline 12 & 25 & 30 & 9 & $1 \mathrm{hr}$. & Diluted, a & added & $5 \mathrm{cc}$. & 98.81 & 25 \\
\hline 1.3 & 25 & 30 & 15 & $1 \mathrm{hr}$. & $\mathrm{CHCl}_{3}$, & titrate & ed with & 99.56 & 25 \\
\hline 14 & 25 & 40 & 9 & $1 \mathrm{hr}$. & $\mathrm{N} / 10 \mathrm{th}$ & hiosulp & phate, & 99.75 & 25 \\
\hline 15 & 25 & 50 & 9 & $1 \mathrm{hr}$. & using st & arch & as in- & 99.75 & 25 \\
\hline 16 & 25 & 50 & 9 & $2 \mathrm{hrs}$. & dicator. & & & 99.75 & 25 \\
\hline
\end{tabular}


Para cresol absorbs bromine much more slowly than either of the other cresols. Under similar experimental conditions, $4 \% / 2$ hours' standing in contact with free bromine results in absorption of only 95.73 per cent. of the theoretical quantity (Exps. $\mathbf{I}, 2$, and 3 ). If concentration of free bromine is increased and the usual quantity of $\mathrm{HCl}$ decreased one-half, the bromine in combination exceeds the amount necessary for the formation of a dibrom$p$-cresol brom or tribromcresol compound and is hours' standing does not result in sufficient decomposition even though the quantity of $\mathrm{KI}$ is doubled (Exps. 4, 5, 6, 7, 8 and 9).

However, an increase in both $\mathrm{HCl}$ and $\mathrm{KI}$ results in a most pronounced reversal ${ }^{\mathrm{r}}$ which is due to the decomposition of dibrom- $p$-cresol brom into dibrom$p$-cresol (Exps. to and II).

Here again the result is directly dependent upon conditions and previous knowledge is necessary on part of the operator.

Now when iodine reacts with $p$-cresol in presence of the condensing agent, sodium acetate, diiodo$p$-cresol is formed in theoretical quantity if sufficient time is allowed for reaction to complete itself.

This reaction is made the basis of a method for the determination of $p$-cresol (Exps. I 2, I3, I4, I5 and I6). The procedure is exactly the same as that given under o-cresol.

\section{SUMMARY.}

r. Usual bromine methods for determination of cresol depend upon fixed conditions presupposing a previous knowledge on the part of the operator, and while they may be of service they do not satisfy the demand for a desirable method.

2. Tribrom-o- and p-cresol brom compounds can not be formed in a manner analogous to the production of 2,4,6-tribrom phenol brom. Dibromcresol brom compounds are formed and finally tribromphenol brom; however, $o$ - and $p$-cresols ćan not be determined volumetrically by a conversion into these compounds.

3. Meta cresol is determined by a conversion into tribrom- $m$-cresol.

4. Ortho and para cresols form diiodo compounds, and this reaction is made the basis of a method for their determination.

5. Meta cresol does not yield diiodo compounds under the same conditions; hence, cresol U. S. P. or any mixture containing $m$-cresol can not be determined by a volumetric iodine method.

Department of Chemical Research,

EII LILIY \& COMPANY. INDIANAPOLIS.

THE ACCURATE VOLUMETRIC DETERMINATION OF PHOSPHORIC ACID IN PHOSPHATE ROCK.

\section{By JOHN G. FAIRChILD.}

Received January 30,1912 .

The method of determining the phosphoric acid content of phosphate rock here described is a modification of Pemberton's caustic alkali titration, which

1 "Zur Quantitativen Bestimmung des Phenols und Parakresols in
Gemischen derselben und halle, 1911, 1288. has the great advantage of being quicker than other volumetric or gravimetric methods. The difficulty experienced in the use of the Pemberton method has been invariably a low result compared with that obtained by the standard method of weighing the phosphoric acid as magnesium pyrophosphate. After close observation of the successive operations whereby the yellow precipitate is dissolved in an excess of standard alkali and this excess titrated after addition of a few drops of phenolphthalein, it was noticed that the final end point was considerably delayed, and this was the more marked the greater the amount of phosphoric acid present or the larger the aliquot parts taken.

In the belief that if this behavior of the indicator toward phosphoric acid could be overcome the method would be very accurate, the suggestion of Sutton ${ }^{x}$ was adopted, namely, to precipitate out the phosphoric acid with barium chloride in excess before titrating the excess of alkali. The results stated below show how the method is improved by this modification.

In the first place low results being obtained in dealing with phosphate rocks by standardizing the alkali solution against microcosmic salt in the old way, it was thought possible that the other salts in the rock solution interfered with the titration. A rock solution whose phosphoric acid content was accurately determined gravimetrically was taken as the standard. The average of four results $(32.69,32.82,32.88$ and 32.93) obtained by using different aliquot ${ }^{2}$ parts of a 2 gram solution was found to be 32.83 per cent. $\mathrm{P}_{2} \mathrm{O}_{5}$. Double precipitations were made after weighing the first precipitate, any calcium sulfate or silica being removed by its solution in sulfuric acid with alcohol. The second weights were only 0.1 to 0.3 mg. less, so that this correction could be disregarded.

The next step was to take an aliquot part, preferably 0.1 gram, add $20 \mathrm{cc}$. of strong ammonia (sp. gr. 0.90), make acid with $\mathrm{I}: \mathrm{I}$ nitric acid, and add slowly $25 \mathrm{cc}$. of warm molybdate solution (about $40^{\circ} \mathrm{C}$.). The temperature of formation of the yellow precipitate here is most important, the limits being $45^{\circ}$ to $55^{\circ} \mathrm{C}$. After shaking for five minutes the precipitate is let stand till cool, then filtered through a $9 \mathrm{~cm}$. No. 590 S. \& S. paper and washed, once with a 2 per cent. nitric acid solution and then with a 2 per cent. potassium nitrate solution till the washings cease to redden blue litmus. Paper and precipitate are then transferred to the original flask and dissolved in an excess of standard alkali; diluted slightly with cold water; three drops of phenolphthalein solution are added and one drop of methyl orange (to give a sharper end point). Excess of alkali is then titrated with standard acid, either nitric or hydrochloric. Next, about $8 \mathrm{cc}$. excess of alkali are again added and Io cc. of a ro per cent. solution of neutral $\mathrm{BaCl}_{2}$, which is usually sufficient to precipitate all the phosphate, the molybdate, and also any carbonate. The important feature is the elimination of the phosphate. After again titrating the excess of alkali the two readings show $32.6 \mathrm{cc}$. and $33 . \mathrm{cc}$. The results of several

I Volumetric Analysis, 9th Ed., p. 113.

2 Pipettes used were standardized to the flask. 